\title{
Light-triggered methylcellulose gold nanoparticle hydrogels for leptin release to inhibit fat stores in adipocytes
}

This article was published in the following Dove Press journal:

International Journal of Nanomedicine

17 October 2017

Number of times this article has been viewed

\section{Zi-Xian Liao' \\ Meng-Chia Liu' \\ Ivan M Kempson ${ }^{2}$ \\ Yu-Chen $\mathrm{Fa}^{\prime}$ \\ Kuo-Yen Huang ${ }^{3,4}$}

'Institute of Medical Science and Technology, National Sun Yat-sen University, Kaohsiung, Taiwan; ${ }^{2}$ Future Industries Institute, University of South Australia, Mawson Lakes, SA, Australia; ${ }^{3}$ nstitute of Biomedical Sciences, Academia Sinica, Taipei, ${ }^{4}$ Graduate Institute of Health Industry Technology and Research Center for Industry of Human Ecology, Chang Gung University of Science and Technology, Taoyuan, Taiwan
Correspondence: Zi-Xian Liao Institute of Medical Science and Technology, National Sun Yat-sen University, Number 70, Lianhai Road, Gushan District, Kaohsiung 804, Taiwan Tel +886 75252000 (extension 584I) Email zxliao@mail.nsysu.edu.tw
Abstract: Leptin is released in response to increased triglyceride storage in adipocytes and impacts body weight, but has drawbacks such as poor therapeutic effect and side effects when delivered systemically. Leptin also modifies adipocyte sensitivity to insulin to inhibit lipid accumulation. Here, light-triggered degradation of hydrogels was used to improve accuracy and effectiveness for sustained and controllable release. In our approach, leptin was entrapped within methylcellulose (MC)-based hydrogels, with incorporation of gold nanoparticles (NP). The incorporation of gold NP into MC hydrogels led to a tunable light irradiation response that dictated the hydrogel release rate of leptin. This manuscript demonstrates feasibility in designing tunable thermosensitive hydrogels for loading multimodality therapeutic agents to enhance the bioactivity of leptin for obesity therapy.

Keywords: leptin, adipocytes differentiation, methylcellulose, gold nanoparticle, degradable hydrogel

\section{Introduction}

Leptin is produced primarily by adipose tissue, and circulating concentrations correlate with the amount of body fat stores. ${ }^{1}$ Although in vitro studies have tested the ability of leptin to directly influence adipocyte metabolism, further evidence indicates leptin inhibits insulin responsiveness of adipose tissue. ${ }^{2}$ Furthermore, leptin modifies adipocyte sensitivity to insulin to inhibit lipid accumulation. In addition, glucose uptake by adipose tissue showed no response to leptin when leptin was administered intravenously ${ }^{3}$ or directly ${ }^{4}$ to adipocytes. Prolonged exposure to leptin did, however, cause a substantial dose-dependent inhibition of insulin-stimulated glucose uptake by the adipocytes. Leptin is a major factor in the modulation of body weight, but suffers from poor therapeutic effect and side effects after systemic administration. ${ }^{5}$

Hydrogels have shown broad utility for tissue regeneration and drug delivery. ${ }^{6-9}$ Furthermore, swelling of $\mathrm{pH}$-sensitive hydrogels in environments with lower $\mathrm{pH}-$ consistent with injured tissues $(\sim \mathrm{pH} 6.0)^{6}$ or tumor microenvironment $(\sim \mathrm{pH} 6.7)^{7}-$ has been promoted by inclusion of amino acids in the polymeric structure. Specifically, protonation of amine groups in response to $\mathrm{pH}$ change increased absorption of water, thus promoting degradation of the hydrogel and enhanced localized release. ${ }^{6,7}$ Among the hydrogels reported on in the literature, a methylcellulose (MC), composed of hydrophilic moieties that are non-immunogenic and non-biofouling of proteins, has shown interesting utility due to its thermogelling properties. ${ }^{10}$ The inverse $\mathrm{MC}$ gel remains injectable, allowing for easy storage, facile timing of injection, and no further manipulation after in vivo injection. 
Concurrently, the photothermal effect of metallic nanoparticles following light excitation has been employed in drug release. ${ }^{11,12}$ Dense, metallic nanoparticles are capable of attenuating incident light via scattering and absorption, leading to localized increase in temperature. In the current work, we designed a drug-loaded injectable MC hydrogel including gold nanoparticles (NPs) to impart light irradiation sensitivity to stimulate thermally triggered drug release. When illuminated, gold NP absorbed the light, resulting in a localized thermal effect and a consequent increase in the release of loaded materials (Figure 1A). Due to the physical effects of biological tissues attenuating light, we further tested long wavelengths of 808 and $980 \mathrm{~nm}$, able to penetrate to depths consistent with subcutaneous adipocytes. MC-gold NP hydrogels were loaded with leptin to regulate fat storage in adipocytes, controlled with light irradiation. Cytotoxicity, photothermal effect, and leptin released from the hydrogels were measured. The release of leptin from hydrogels at different conditions toward adipocytes was used to verify light irradiation-mediated release with in-vitro studies.

A Leptin-embedded
MC-gold NP hydrogels

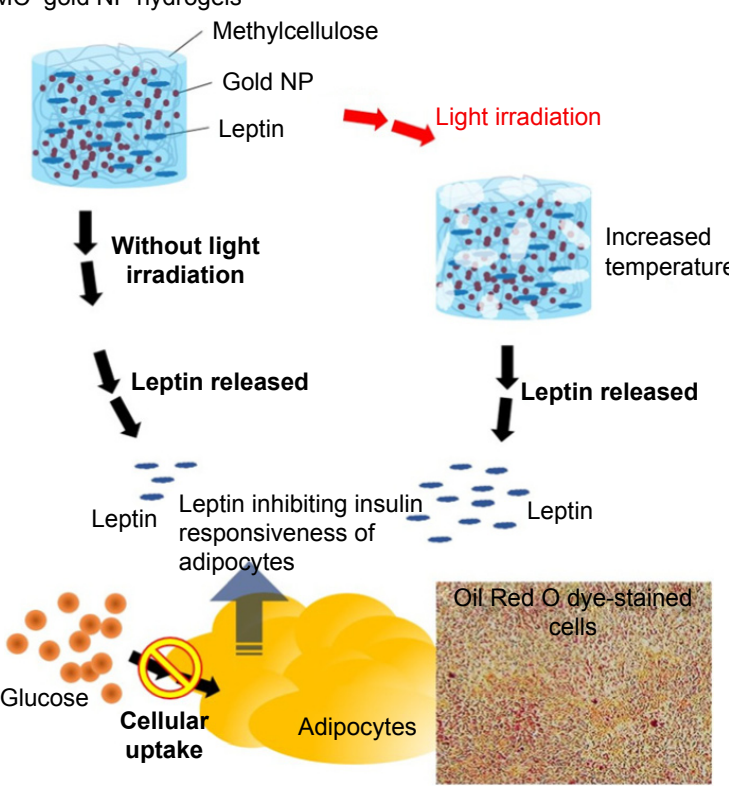

Inhibition of lipid storage in adipocytes

\section{Materials and methods}

Materials

We purchased $\mathrm{MC}\left(\mathrm{Mw}=14,000 \mathrm{~g} \mathrm{~mol}^{-1}\right)$, phosphate-buffered saline (PBS, pH 7.4), Oil Red O dye, dexamethasone, insulin, isobutylmethylisobutylxanthine (IBMX), leptin from mouse (>98\%), and 4',6-diamidino-2-phenylindole dihydrochloride (DAPI) from Sigma-Aldrich Co. (St Louis, MO). CellTiter $96^{\circledR} \mathrm{AQ}_{\text {ueous }}$ One Solution Cell Proliferation Assay kit for the 3-(4,5-dimethylthiazol-2-yl)-5-(3-carboxymethoxyphenyl)-2 -(4-sulfophenyl)-2H-tetrazolium (MTS) assay was purchased from Promega (Madison, WI). Bare gold NPs (A11-20, size: $20 \mathrm{~nm}$ ) were purchased from Nanopartz ${ }^{\mathrm{TM}}$ Inc (Loveland, Colorado). For transmission electron microscopy (TEM, JEOL JEM-1400) analysis, a drop of gold NP solution was allowed to air-dry onto a Formvar-carbon-coated 200-mesh copper grid. TEM images were imaged on a JEOL-1400 transmission electron microscope operating at an accelerating voltage of $100 \mathrm{kV}$. The UV-vis absorption spectra of the gold NP solutions that were prepared under deionized water were measured using a UV-vis spectrophotometer (Tecan's Sunrise; Tecan Trading AG, Männedorf, Switzerland).

B

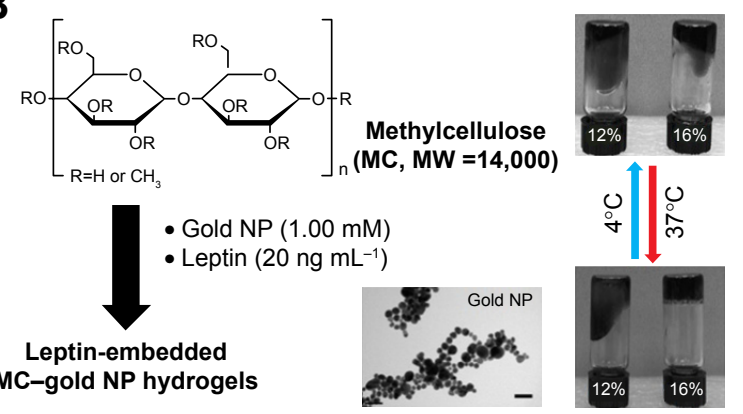

C

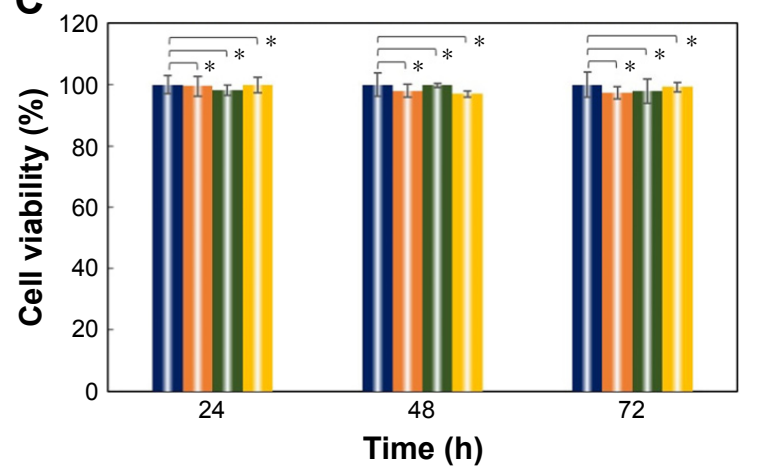

I Control "| Gold NP |" MC ॥ MC-gold NP hydrogels

Figure I Light-sensitive MC-gold NP hydrogels.

Notes: (A) A conceptual representation of a light-triggered MC-gold NP hydrogel for leptin release to inhibit fat stores in adipocytes. Light irradiation increases porosity and promotes efflux of payload material in a controlled, tunable manner. (B) Schematic illustration of the synthesis of leptin-embedded MC-gold NP hydrogels. Leptin was embedded into MC-gold NP hydrogels and exposed to $37^{\circ} \mathrm{C}$ for $5 \mathrm{~min}$ to facilitate the formation of MC-gold NP hydrogels. The TEM image is of gold NPs. Bar $=50 \mathrm{~nm}$. Photographs (right panel) of MC-gold NP hydrogels with I2\% or I6\% (v/v) MC. A complete hydrogel was achieved at I6\% (v/v). (C) Viability of 3T3-LI cells after exposure to various treatments. Cell viability is given as the percentage of viable cells remaining after treatment for 24,48 , or $72 \mathrm{~h}$ when compared with unexposed cells. Cell numbers were determined by the standard MTS assay $(* P>0.15$; based on a two-tailed $t$-test, assuming unequal variances). The bars represent the mean \pm standard deviation $(n=6)$. Abbreviations: MC, methylcellulose; MTS, 3-(4,5-dimethylthiazol-2-yl)-5-(3-carboxymethoxyphenyl)-2-(4-sulfophenyl)-2H-tetrazolium; NP, nanoparticle; TEM, transmission electron microscopy. 


\section{Cell culture and differentiation}

The Mouse embryonal fibroblast 3T3-L1 (CL-173, ATCC) cell lines were maintained in Dulbecco's Modified Eagle's Medium (DMEM) with 4,500 $\mathrm{mg} \mathrm{L}^{-1}$ glucose, $10 \%$ fetal bovine serum (FBS), $100 \mathrm{U} \mathrm{mL}^{-1}$ penicillin, and $100 \mu \mathrm{g} \mathrm{mL}^{-1}$ streptomycin.

For differentiation protocol of 3T3-L1 cells to adipocytes, ${ }^{13}$ 3T3-L1 cells were cultured in Basal Medium I (BMI; DMEM supplemented with 4,500 $\mathrm{mg} \mathrm{L}^{-1}$ glucose, $10 \% \mathrm{FBS}, 100 \mathrm{UmL}^{-1}$ penicillin, and $100 \mu \mathrm{g} \mathrm{mL}^{-1}$ streptomycin) at designated Day 1 . At 3 days post-confluence (Day 3), cells were induced to differentiate with Differentiation Medium I (DMI; DMEM supplemented with $1 \mu \mathrm{M}$ dexamethasone, $0.5 \mathrm{mM}$ isobutylmethylxanthine, and $10 \mu \mathrm{g} \mathrm{mL}^{-1}$ insulin). After 2 days (Day 5), the medium were replaced with Differentiation Medium II (DMII; DMEM supplemented with $10 \% \mathrm{FBS}$ and $10 \mu \mathrm{g} \mathrm{mL}^{-1}$ insulin). At Day 7, the cells were maintained in the BMI and, subsequently, the cells were re-fed every $24 \mathrm{~h}$ with BMI. All cells were cultured in a $37^{\circ} \mathrm{C}$ incubator with $5 \% \mathrm{CO}_{2}$.

\section{Preparation of hydrogels incorporating metal nanoparticles}

The MC was dissolved in PBS to a final concentration of $12 \%$ or $16 \%(\mathrm{v} / \mathrm{v})$ at $4^{\circ} \mathrm{C}$. Subsequently, the gold NP solution was added into the $\mathrm{MC}$ solution, with stirring, resulting in final concentrations of $0.125,0.25,0.5,1.00$, or $2.00 \mathrm{mM}$. The mixed solutions were placed in cylindrical containers and exposed to $37^{\circ} \mathrm{C}$, from $4^{\circ} \mathrm{C}$ onward, for $5 \mathrm{~min}$ to facilitate the formation of $\mathrm{MC}$-gold NP hydrogels $(6.0 \mathrm{~mm}$ diameter, $2.0 \mathrm{~mm}$ height), shown schematically in Figure 1B.

\section{Toxicity of laser irradiation or hydrogels by MTS assay}

For the MTS assay, $2 \times 10^{5} 3 \mathrm{~T} 3$-L1 cells were seeded in each of the wells of a 24-well plate and fed with culture medium overnight. A porous polyester Transwell ${ }^{\mathrm{TM}}$ insert with a pore size of $0.4 \mu \mathrm{m}$ was placed in each well of the 24 -well plate. Then, tested hydrogels were placed into the Transwell ${ }^{\mathrm{TM}}$ insert. The 3T3-L1 cells were then exposed to test hydrogels or laser wavelength of $520 \mathrm{~nm}(1.0 \mathrm{~mW}), 808 \mathrm{~nm}(1.5 \mathrm{~mW})$, or $980 \mathrm{~nm}(1.5 \mathrm{~mW})$ for different periods of irradiation for 24 , 48 , or $72 \mathrm{~h}$ incubation. The CellTiter $96^{\circledR}$ AQueous One solution cell proliferation assay system (Promega, Madison, WI, USA) was used to evaluate cell proliferation and observation of the optical density (OD) of formazan at $490 \mathrm{~nm}$, quantified cell viability. The reagent contained a tetrazolium compound 3-(4,5-dimethylthiazol-2-yl)-5-(3-carboxymethoxyphenyl)2-(4-sulfophenyl)-2H-tetrazolium and inner salt (MTS), and the reduction of MTS achieved by untreated cells was set at
$100 \%$, and that of test cells was expressed as a percentage of untreated cells. ${ }^{14-16}$ Data are shown as the mean \pm the standard deviation for six independent experiments.

\section{Temperature measurement of hydrogels}

The concentration of $16 \%(\mathrm{v} / \mathrm{v}) \mathrm{MC}$ hydrogel was chosen for subsequent measurements. Observation of MC-gold NP hydrogel at various gold NP concentrations $(0.125,0.25,0.5$, 1.00 , or $2.00 \mathrm{mM}$ ) and temperature triggered by different laser wavelengths of $520 \mathrm{~nm}(1.0 \mathrm{~mW}), 808 \mathrm{~nm}(1.5 \mathrm{~mW})$, or $980 \mathrm{~nm}(1.5 \mathrm{~mW})$ for irradiation of various time periods was measured with a thermometer. The tip of the laser fiber was mounted above the hydrogel. Data are shown as the mean \pm the standard deviation for three independent experiments.

\section{Leptin release from hydrogels}

For preparation of leptin-embedded MC-gold NP hydrogels, the aqueous leptin solution $\left(20 \mathrm{ng} \mathrm{mL} \mathrm{mL}^{-1}\right)$ was added into the mixture $(1 \mathrm{~mL})$ as described earlier. To assess the leptin released from these hydrogels, the leptin-embedded MC-gold NP hydrogels were placed in the Transwell ${ }^{\mathrm{TM}}$ insert and incubated in complete DMEM $(0.5 \mathrm{~mL})$ at $37^{\circ} \mathrm{C}$ for irradiation of laser wavelength $(980 \mathrm{~nm}: 10 \mathrm{~min})$ every day for 5 days. Leptin released from these hydrogels was determined by the Mouse Leptin ELISA Kit (Sigma-Aldrich Co., USA). Data are shown as the mean \pm the standard deviation for four independent experiments.

\section{In vitro studies and analysis}

We seeded $2 \times 10^{5} 3 \mathrm{~T} 3$-L1 cells in each well of a 24 -well plate, and followed the protocol as described in the subsection on differentiation of adipocytes. On Day 5 in the process of adipocyte differentiation, a porous polyester Transwell ${ }^{\mathrm{TM}}$ insert (Corning, NY) with a pore size of $0.4 \mu \mathrm{m}$ was placed in each well. The leptin-embedded MC-gold NP hydrogels $(6.0 \mathrm{~mm}$ diameter, $2.0 \mathrm{~mm}$ height) were placed in the Transwell ${ }^{\mathrm{TM}}$ insert and incubated in complete $\operatorname{DMEM}(0.5 \mathrm{~mL})$ at $37^{\circ} \mathrm{C}$ for laser irradiation $(520 \mathrm{~nm}: 4 \mathrm{~min}$; $808 \mathrm{~nm}$ : $2 \mathrm{~min}$; or $980 \mathrm{~nm}$ : $10 \mathrm{~min}$ ) every day for 5 days. The tip of the laser fiber was mounted above the hydrogel. Untreated adipocytes were used as the control.

To identify adipocyte accumulation, fat droplets in 3T3-L1 cells were stained with Oil Red O dye. ${ }^{17,18}$ Before the Oil Red $\mathrm{O}$ dye staining, treated cells were washed with PBS, fixed with 4\% paraformaldehyde, and washed twice with PBS. Cells were then treated with isopropanol (60\%) for $1 \mathrm{~min}$ and then stained in the Oil Red O dye solution $(0.18 \%$ [w/v] Oil Red O dye in 60\% isopropanol) for 30-40 mins. 
The treated cells were washed with isopropanol (60\%) and twice with PBS. The Oil Red O dye-stained cells were observed in PBS under a microscope. Quantification of Oil Red $\mathrm{O}$ dye was performed by extracting the dye using $100 \%$ isopropanol and OD was then measured at a wavelength of $520 \mathrm{~nm}$.

Total RNA was extracted from homogenized cell lysates using the Total RNA Isolation Kit (GenedireX, CA, USA), and first-strand cDNA was synthesized with the GScript Enzyme Mix (GeneDireX, CA, USA) according to the manufacturer's instructions. The peroxisome proliferator-activated receptor $\gamma$ (PPAR- $\gamma$ ) cDNA was measured for quantitative real-time reverse-transcription polymerase chain reaction (qRT-PCR) analysis using the following sequences of primers of PPAR- $\gamma$ : sense-CGCTGATGCACTGCCTATGA; antisense-AGAGGTCCACAGAGCTGATTCC. $\beta$-actin: sense-TGTCCACCTTCCAGCAGATGT; antisenseAGCTCAGTAACAGTCCGCCTAGA.

\section{Results and discussion}

\section{Toxicity and temperature of MC-gold NP} hydrogels

For preparation of injectable leptin-embedded $\mathrm{MC}$-gold nanoparticles (NP) hydrogels (Figure 1B), an effective loading-matrix should exhibit minimal toxicity. Cytotoxicity of MC hydrogels, gold NP, or leptin-embedded MC-gold NP hydrogels to 3T3-L1 cells was evaluated by MTS assay after culturing for 24,48 , or $72 \mathrm{~h}$. Cells with no treatment were used as a control group. No cytotoxicity was observed for any of MC hydrogels, gold NP (Conc: $1.00 \mathrm{mM}$ ), or leptinembedded MC-gold NP hydrogels incubated with mouse embryonal fibroblast 3T3-L1 cells $(P>0.15)$ (Figure 1C).

The photo-thermal effect of metallic nanoparticles upon light-excitation can trigger release of pre-loaded drugs from gels and carriers. ${ }^{11,12}$ In our experiment, the commercial gold NP yield the highest absorbance peak around $520 \mathrm{~nm}$ (Figure S1). Due to the major concern of light bio-penetration, we also applied two wavelengths of 808 and $980 \mathrm{~nm}$ into the photo-thermal treatment to be more consistent with treatment at a depth comprising subcutaneous tissues. To determine the effect of incorporated gold NP concentration on the temperature of MC-gold NP hydrogels, hydrogels were immersed and incubated at $\mathrm{pH}$ 7.4. The tip of the laser fiber was mounted above the hydrogel. The results showed that the temperature of the $\mathrm{MC}-$ gold $\mathrm{NP}$ hydrogels increased from $33^{\circ} \mathrm{C} \pm 0.3^{\circ} \mathrm{C}$ to $48^{\circ} \mathrm{C} \pm 0.6^{\circ} \mathrm{C}$ with the incorporation of gold NP at $1.00 \mathrm{mM}$ for light irradiation using $980 \mathrm{~nm}$ at 0 and $10 \mathrm{~min}$, respectively (Figure 2).

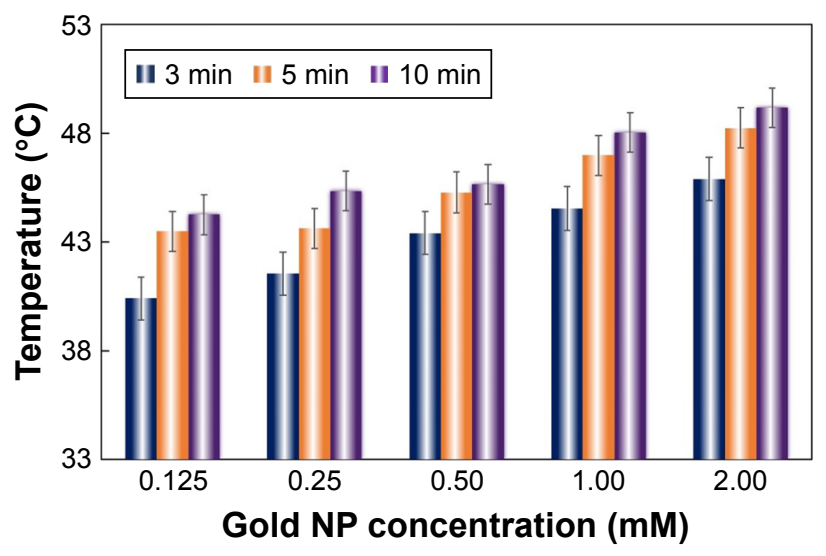

Figure 2 Temperature of MC-gold NP hydrogels under light irradiation.

Notes: Temperature achieved by irradiation with $980 \mathrm{~nm}(1.5 \mathrm{~mW})$ for 3 , 5, or 10 min for varying NP content. The tip of the laser fiber was mounted above the hydrogel. The bars represent the mean \pm standard deviation $(n=3)$.

Abbreviations: MC, methylcellulose; NP, nanoparticle.

The incorporation of gold NP had a positive correlation on the temperature with considerable increases achieved even for the lowest concentration of $0.125 \mathrm{mM}$. At $2.00 \mathrm{mM}$ gold NP concentration, some aggregation was observed. The temperature of MC-gold NP hydrogels under light irradiation using $520 \mathrm{~nm}$ or $808 \mathrm{~nm}$ also presented similar increase (Figure S2). In addition, when laser wavelength of $980 \mathrm{~nm}$ for light irradiation was increased to $10 \mathrm{~min}$, cell viability was still maintained at $\sim 90 \%(P>0.15)$ (Figure S3A). In contrast, laser wavelength of $808 \mathrm{~nm}$ for light irradiation of $2 \mathrm{~min}$, resulted in cell viability $>75 \%$ compared with laser wavelength of $520 \mathrm{~nm}(P<0.05)$, indicating that laser wavelength of $808 \mathrm{~nm}$ exhibited a significantly toxicity toward the cells. (Figure S3B). We subsequently chose a gold NP concentration of $1.00 \mathrm{mM}$ and laser wavelength of $980 \mathrm{~nm}$ for light irradiation of $10 \mathrm{~min}$ in subsequent in vitro studies.

\section{Differentiation of 3T3-LI cells to adipocytes}

In this culture protocol of adipocyte differentiation, mature adipocytes normally differentiated after Day 7. Staining for lipids, or fat, is commonly achieved with Oil Red O dye. ${ }^{19}$ Consequently, the quantification of lipid storage in cells and its correlation with Oil Red O dye-stained cells was determined by measuring OD of Oil Red $\mathrm{O}$ dye extracted from treated cells (Figure 3A). The OD value of Oil Red $\mathrm{O}$ dye increased gradually during the incubation period for the Basal Medium I (BMI, Day 0-Day 3), Differentiation Medium I (DMI, Day 3-Day 5), and Differentiation Medium II (DMII, Day 5-Day 7). The highest OD value was achieved at Day 9, and subsequently OD value decreased slowly after this day. Consistent with OD measurements, 
A
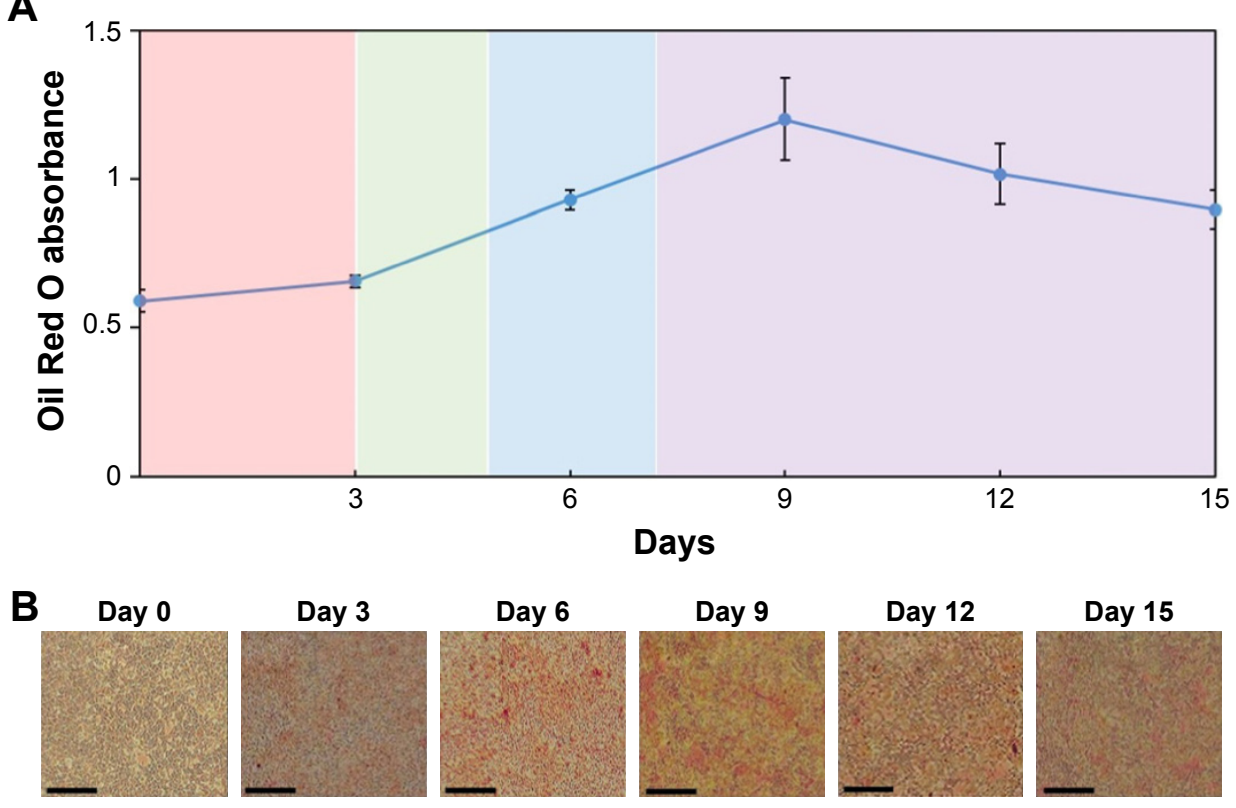

Figure 3 Differentiation of 3T3-LI cells to adipocytes.

Notes: (A) Quantification of lipid storage in cells was measured by the optical density of Oil Red O dye, which was extracted from treated cells. The bars represent the mean \pm standard deviation $(n=3)$. (B) Photographs of Oil Red $O$ dye-stained cells at different periods. Bars $=200 \mu \mathrm{m}$.

we observed significant Oil Red $\mathrm{O}$ dye-stained adipocytes at Day 6, Day 9, and Day 12 with microscopy as shown in Figure 3B. Overall, we chose the mature adipocytes at Day 5-Day 9 for the measurement of effect of leptin on fat stores in subsequent in vitro studies.

\section{Leptin released from leptin-embedded MC-gold NP hydrogels}

To evaluate leptin concentration post-treatment, we used Mouse Leptin ELISA Kit to detect leptin released from these leptin-embedded MC-gold NP hydrogels. The concentration of leptin released from hydrogels increased gradually during the incubation period for the leptin-embedded MC-gold NP hydrogels incubated with light irradiation (980 nm; $10 \mathrm{~min}$ ) every day (Figure 4A). Leptin release was significantly stimulated with light irradiation compared with treatment without light irradiation $(P<0.05)$. In addition, control samples of leptin indicated a similar bioactivity with or without exposure to light irradiation. Taken together, the results imply that leptin released post-treatment with light irradiation did not affect bioactivity.

To investigate the effect of leptin released from these hydrogels on lipid storage in adipocytes, hydrogels were placed into the Transwell ${ }^{\mathrm{TM}}$ insert. The 3T3-L1 cells after post-differentiation (Day 5) were then exposed to these hydrogels under different conditions. On Day 7 or 9, leptin-embedded MC-gold NP hydrogels subjected to light irradiation
(980 $\mathrm{nm}$ ) every day for 10 min and leptin with or without light irradiation showed similar inhibition of lipid storage $(P<0.05$; Figure 4B). Furthermore, the leptin-embedded $\mathrm{MC}$-gold NP hydrogels treated with light irradiation displayed an $\sim 50 \%$ inhibition of lipid storage compared with control on day $7(222 \%, P<0.05)$ or on day $9(198 \%$, $P<0.05)$. In Figure $4 \mathrm{C}$, we observed micrographs of adipocytes when the leptin-embedded MC-gold NP hydrogels under light irradiation were utilized and coincides with the relative lipid storage shown in Figure 4B. In addition, leptinembedded MC-gold NP hydrogels under light irradiation using 520 or $808 \mathrm{~nm}$ showed consistent results when using $980 \mathrm{~nm}$ (Figure S4). Overall, these results confirmed the considerable effect of leptin released from leptin-embedded MC-gold NP hydrogels on decreasing the amount of fat stores in adipocytes after light irradiation (Figure 4B).

\section{In vitro assay}

In addition to its importance in adipogenesis, PPAR- $\gamma$ plays an important role in regulating fat storage. ${ }^{20}$ Overall, leptin modulates mRNA levels of PPAR- $\gamma$ in adipocytes (Figure 5A). ${ }^{21}$ Data analyzed by gel electrophoresis for PPAR $-\gamma$ cDNA are consistent with the previous finding that the leptin released from MC-gold NP hydrogels under light irradiation (Lanes $\mathrm{G}-\mathrm{I}$ ) and that leptin under various conditions (Lanes B, D, E, and F) resulted in lower PPAR- $\gamma$ cDNA (Figure 5B). Conversely, negative control (Lane A) and 


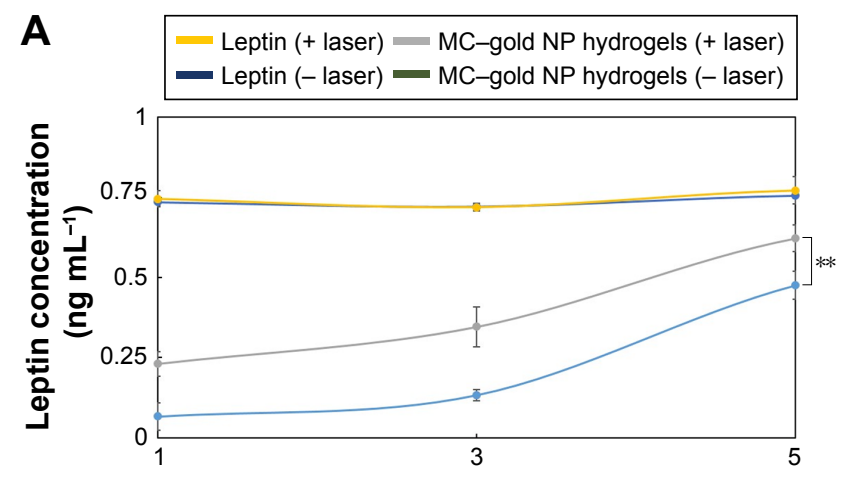

B

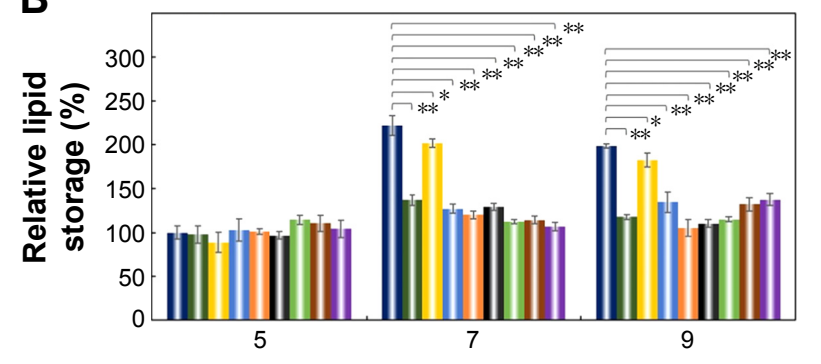

Day

\section{C}
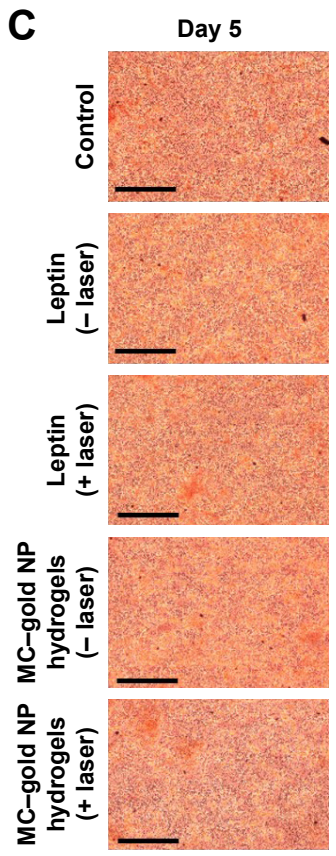

Day 9
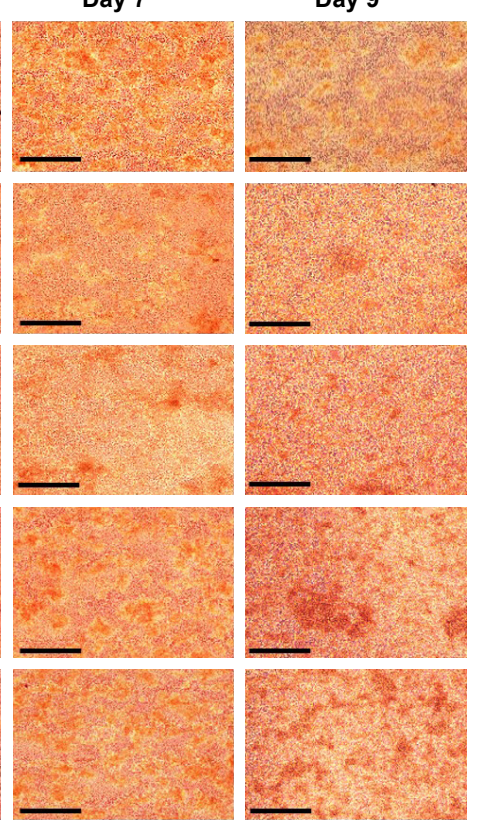

\footnotetext{
I Control " Leptin (- laser) "I MC-gold NP hydrogels (- laser)

u Leptin $(980 \mathrm{~nm}) \quad$ " Leptin $(808 \mathrm{~nm}) \quad$ " Leptin $(520 \mathrm{~nm})$

"I MC-gold NP hydrogels $(980 \mathrm{~nm})$ "1 MC-gold NP hydrogels

II MC-gold NP hydrogels $(520 \mathrm{~nm}) \quad(808 \mathrm{~nm})$
}

Figure 4 Light-triggered release of leptin from leptin-embedded MC-gold NP hydrogels.

Notes: (A) Measurement of the leptin release. Leptin-embedded MC-gold NP hydrogels were placed in Transwell ${ }^{\mathrm{TM}}$ inserts (Corning, New York, NY, USA) and incubated in complete DMEM at $37^{\circ} \mathrm{C}$ for irradiation $(980 \mathrm{~nm}$; $10 \mathrm{~min}$ ) every day for 5 days. Leptin release was determined by Mouse Leptin ELISA Kit (Sigma-Aldrich Co., St Louis, MO, USA; $* * P<0.05$; based on a two-tailed $t$-test, assuming unequal variances). The bars represent the mean \pm standard deviation ( $\mathrm{n}=4$ ). Lines are included to guide the eye. (B) Quantification of lipid storage in cells was measured by the optical density (OD) of Oil Red O dye post-incubation under various conditions of light irradiation ( $* P>0.15$; $* * P<0.05$; based on a two-tailed $t$-test, assuming unequal variances). The bars represent the mean \pm standard deviation ( $n=3$ ). (C) Photographs of Oil Red $O$ dye-stained cells at different periods post-treatment. Bars $=200 \mu \mathrm{m}$.

Abbreviations: -, without; +, with; MC, methylcellulose; NP, nanoparticle.

\section{A}

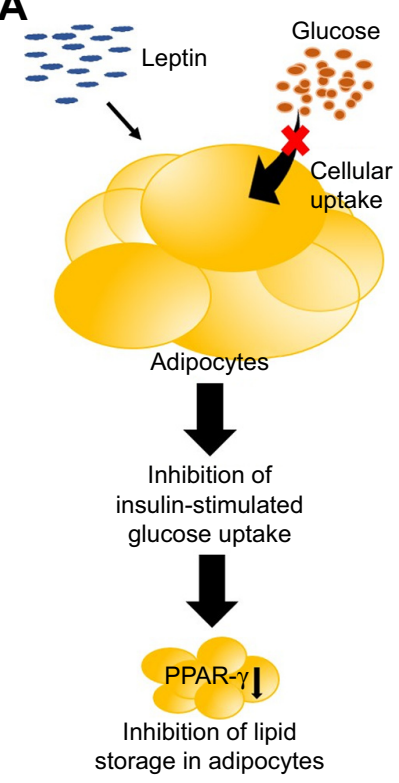

B

\begin{tabular}{|c|c|c|c|c|c|c|c|c|c|}
\hline & A & B & C & D & $\mathbf{E}$ & $\mathbf{F}$ & G & $\mathbf{H}$ & I \\
\hline PPAR- $\gamma$ & - & and & 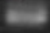 & 8 & 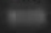 & ear & 5 & 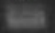 & 5 \\
\hline -actin & & & & & & & & & \\
\hline
\end{tabular}

\section{A - Control \\ $\mathrm{B}$ - Leptin (without light irradiation) \\ C - Leptin-embedded MC-gold NP} hydrogel (without light irradiation)

D - Leptin (with light irradiation; $980 \mathrm{~nm}$ )

E - Leptin (with light irradiation; $808 \mathrm{~nm}$ )

$\mathrm{F}$ - Leptin (with light irradiation; $520 \mathrm{~nm}$ )

G - Leptin-embedded MC-gold NP hydrogel (with light irradiation; $980 \mathrm{~nm}$ )

$\mathrm{H}$ - Leptin-embedded MC-gold NP hydrogel (with light irradiation; $808 \mathrm{~nm}$ )

I - Leptin-embedded MC-gold NP hydrogel (with light irradiation; $520 \mathrm{~nm}$ )

Figure 5 Effect of leptin on the mRNA levels of PPAR- $\gamma$ in adipocytes.

Notes: (A) A conceptual representation of the leptin-modulated mRNA levels of PPAR- $\gamma$ in adipocytes. (B) Gel electrophoresis. PPAR- $\gamma$ cDNA was measured for quantitative real-time reverse transcription polymerase chain reaction analysis. $\beta$-actin cDNA was used as an internal standard. Abbreviations: MC, methylcellulose; NP, nanoparticle. 
MC-gold NP hydrogels without light irradiation (Lane C) achieved significantly greater PPAR- $\gamma$ cDNA levels than the other groups. These data imply that successful passive delivery of leptin released from these hydrogels to adipocytes results in localized and highly efficient inhibition of fat storages.

\section{Conclusion}

MC-gold NP hydrogels with potential for efficient and localized release triggered by light irradiation were developed. The real-time temperature-dependent degradation rate of the MC-gold NP hydrogels could be controlled by the proportion of gold NP included. Leptin was embedded into MC-gold NP hydrogels and then effectively released with light irradiation. The released leptin could accumulate in cells efficiently. Such light-triggered leptin release from hydrogels has broad potential for drug delivery.

\section{Acknowledgment}

This work was supported through the Taiwan Ministry of Science and Technology grants (numbers MOST105-2628E-110-001-MY3 and MOST105-2628-B-110-004-MY3).

\section{Disclosure}

The authors report no conflicts of interest in this work.

\section{References}

1. Ruud J, Brüning JC. Metabolism: light on leptin link to lipolysis. Nature. 2015;527(7576):43-44.

2. Harris RB. Direct and indirect effects of leptin on adipocyte metabolism. Biochim Biophys Acta. 2014;1842(3):414-423.

3. Kamohara S, Burcelin R, Halaas JL, Friedman JM, Charron MJ. Acute stimulation of glucose metabolism in mice by leptin treatment. Nature. 1997; 389(6649):374-377.

4. Huo L, Münzberg H, Nillni EA, Bjørbaek C. Role of signal transducer and activator of transcription 3 in regulation of hypothalamic trh gene expression by leptin. Endocrinology. 2004;145(5):2516-2523.

5. Clark KA, MohanKumar SM, Kasturi BS, MohanKumar PS. Effects of central and systemic administration of leptin on neurotransmitter concentrations in specific areas of the hypothalamus. Am J Physiol Regul Integr Comp Physiol. 2006;290(2):R306-R312.

6. Zeng YF, Tseng SJ, Kempson IM, Peng SF, Wu WT, Liu JR. Controlled delivery of recombinant adeno-associated virus serotype 2 using $\mathrm{pH}-$ sensitive poly(ethylene glycol)-poly-L-histidine hydrogels. Biomaterials. 2012;33(36):9239-9245.
7. Lin CW, Tseng SJ, Kempson IM, Yang SC, Hong TM, Yang PC. Extracellular delivery of modified oligonucleotide and superparamagnetic iron oxide nanoparticles from a degradable hydrogel triggered by tumor acidosis. Biomaterials. 2013;34(17):4387-4393.

8. Fabiano A, Bizzarri R, Zambito Y. Thermosensitive hydrogel based on chitosan and its derivatives containing medicated nanoparticles for transcorneal administration of 5-fluorouracil. Int J Nanomedicine. 2017; 12:633-643.

9. Cho SH, Kim A, Shin W, et al. Photothermal-modulated drug delivery and magnetic relaxation based on collagen/poly(gamma-glutamic acid) hydrogel. Int J Nanomedicine. 2017;12:2607-2620.

10. Pakulska MM, Vulic K, Tam RY, Shoichet MS. Hybrid crosslinked methylcellulose hydrogel: a predictable and tunable platform for local drug delivery. Adv Mater. 2015;27(34):5002-5008.

11. Crawford BM, Shammas RL, Fales AM, et al. Photothermal ablation of inflammatory breast cancer tumor emboli using plasmonic gold nanostars. Int J Nanomedicine. 2017;12:6259-6272.

12. Fomina N, Sankaranarayanan J, Almutairi A. Photochemical mechanisms of light-triggered release from nanocarriers. Adv Drug Deliv Rev. 2012; 64(11):1005-1020.

13. Reed BC, Lane MD. Insulin receptor synthesis and turnover in differentiating 3T3-L1 preadipocytes. Proc Natl Acad Sci USA. 1980;77(1): 285-289.

14. Tseng SJ, Liao ZX, Kao SH, et al. Highly specific in vivo gene delivery for p53-mediated apoptosis and genetic photodynamic therapies of tumour. Nat Commun. 2015;6:6456.

15. Tseng SJ, Huang KY, Kempson IM, et al. Remote control of lighttriggered virotherapy. ACS Nano. 2016;10(11):10339-10346.

16. Liao ZX, Kempson IM, Fa YC, et al. Magnetically guided viral transduction of gene-based sensitization for localized photodynamic therapy to overcome multi drug resistance in breast cancer cells. Bioconjug Chem. 2017;28(6):1702-1708.

17. Yamaguchi J, Tanaka $T$, Saito H, et al. Echinomycin inhibits adipogenesis in 3T3-L1 cells in a HIF-independent manner. Sci Rep. 2017; $7(1): 6516$

18. Nguyen MT, Csermely P, Sőti C. Hsp90 chaperones PPAR gamma and regulates differentiation and survival of 3T3-L1 adipocytes. Cell Death Differ. 2013;20(12):1654-1663.

19. Argenta DF, de Mattos CB, Misturini FD, et al. Factorial design applied to the optimization of lipid composition of topical antiherpetic nanoemulsions containing isoflavone genistein. Int J Nanomedicine. 2014;9: $4737-4747$.

20. Farmer SR. Transcriptional control of adipocyte formation. Cell Metab. 2006;4(4):263-273.

21. Cabrero A, Cubero M, Llaverias G, et al. Leptin down-regulates peroxisome proliferator-activated receptor gamma (PPAR-gamma) mRNA levels in primary human monocyte-derived macrophages. Mol Cell Biochem. 2005;275(1-2):173-179. 


\section{Supplementary materials}

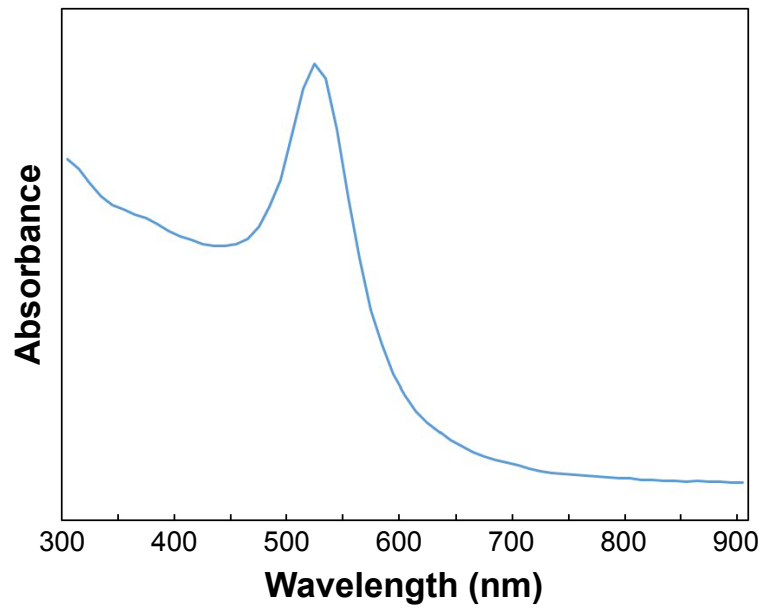

Figure SI Characterization of gold nanoparticles (NPs).

Note: UV-vis absorption spectra of gold NPs, revealing absorption peak at approximately $520 \mathrm{~nm}$.

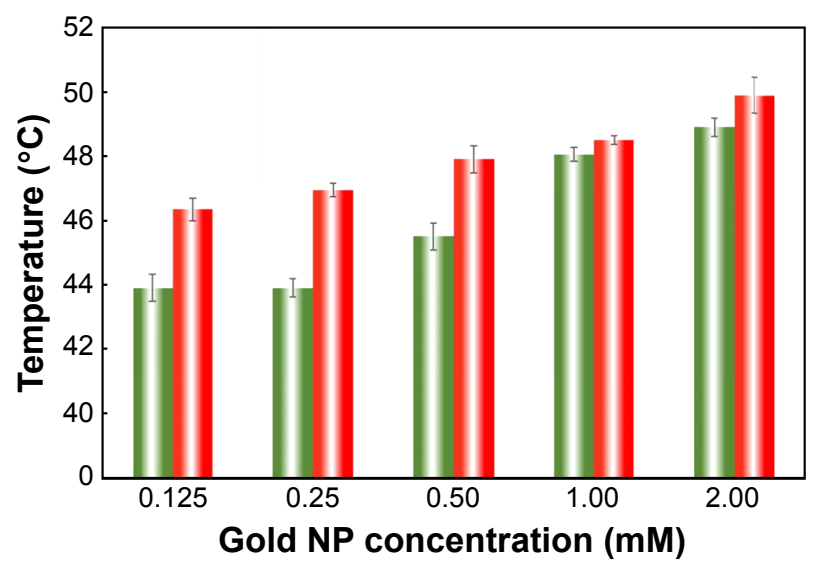

II $520 \mathrm{~nm}, 4 \mathrm{~min} \quad I 1808 \mathrm{~nm}, 2 \mathrm{~min}$

Figure S2 Temperature of MC-gold NP hydrogels under light irradiation. Notes: Temperature was measured for MC-gold NP hydrogels at various gold NP concentrations after irradiation ( $520 \mathrm{~nm}: 4 \mathrm{~min}, 808 \mathrm{~nm}: 2 \mathrm{~min})$. The tip of the laser fiber was mounted above the hydrogel. The bars represent the mean \pm standard deviation $(n=3)$.

Abbreviations: MC, methylcellulose; NP, nanoparticle.

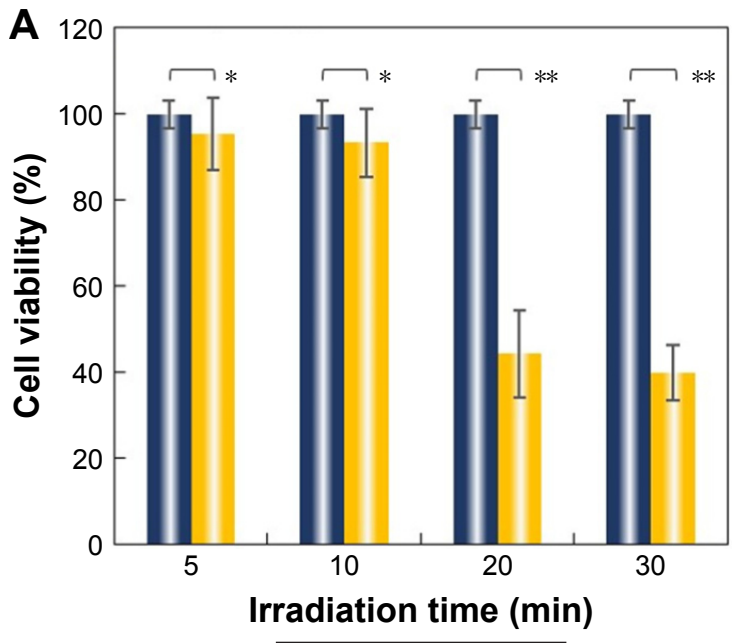

II Control II $980 \mathrm{~nm}$

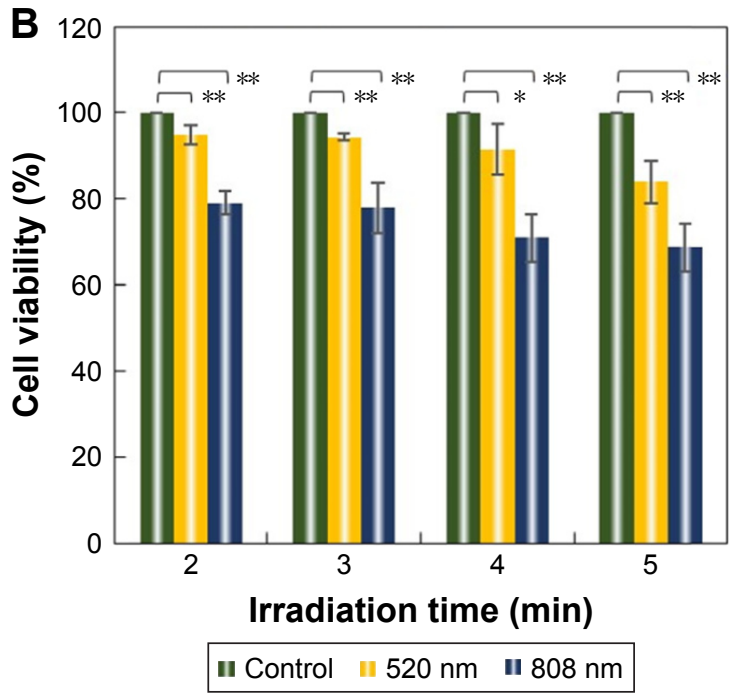

Figure S3 Cell viability after light irradiation.

Notes: Viability of 3T3-LI cells after exposure to laser wavelengths of $980 \mathrm{~nm}$ (A) and 520 and $808 \mathrm{~nm}$ (B). Cell viability is given as the percentage of viable cells remaining after various treatments compared against the unexposed cells. Cell numbers were determined by the standard MTS assay $(* P>0.15 ; * * P<0.05$; based on a two-tailed $t$-test, assuming unequal variances). The bars represent the mean \pm standard deviation $(\mathrm{n}=6)$

Abbreviation: MTS, 3-(4,5-dimethylthiazol-2-yl)-5-(3-carboxymethoxyphenyl)2-(4-sulfophenyl)-2H-tetrazolium. 


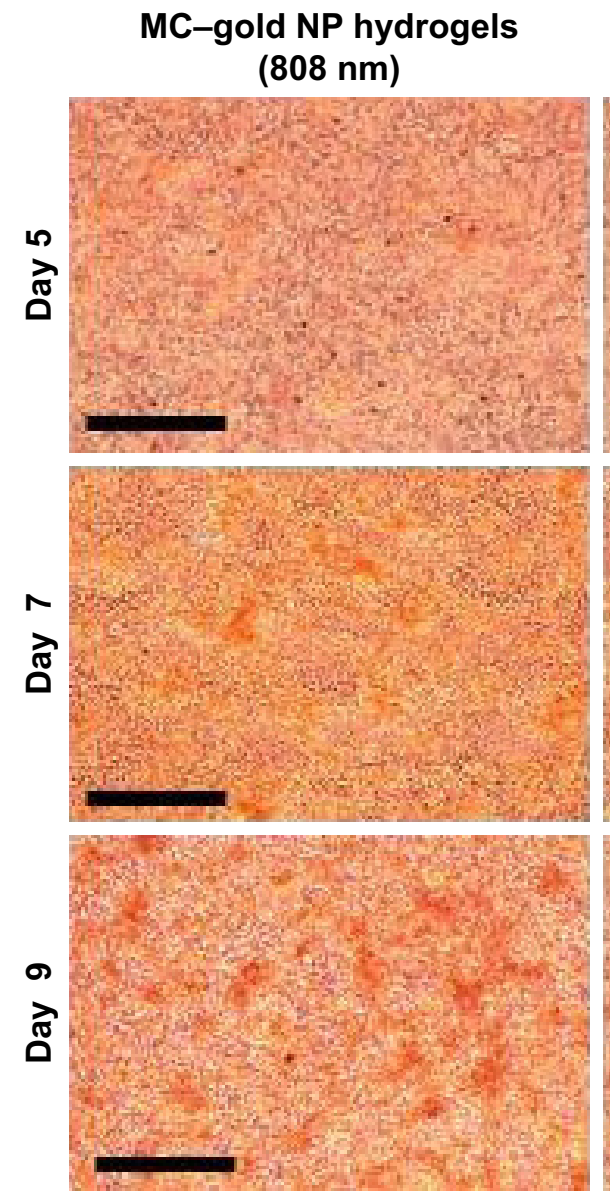

\section{MC-gold NP hydrogels \\ $(520 \mathrm{~nm})$}
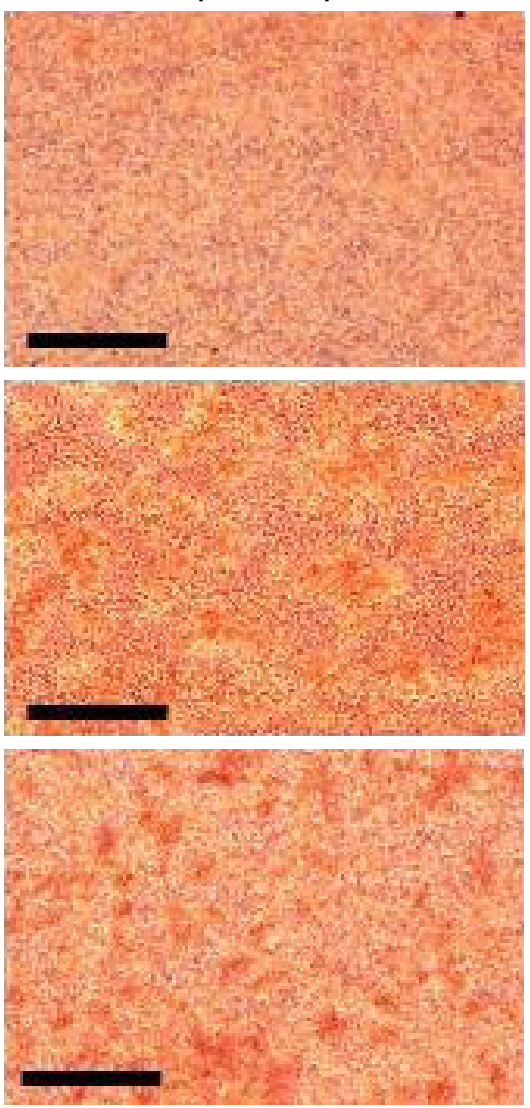

Figure S4 The lipid storage in adipocytes post-treatment.

Notes: Photographs of Oil Red O dye-stained cells at different periods post-treatment. Bars $=200 \mu \mathrm{m}$.

Abbreviations: MC, methylcellulose; NP, nanoparticle.

International Journal of Nanomedicine

\section{Publish your work in this journal}

The International Journal of Nanomedicine is an international, peerreviewed journal focusing on the application of nanotechnology in diagnostics, therapeutics, and drug delivery systems throughou the biomedical field. This journal is indexed on PubMed Central, MedLine, CAS, SciSearch $®$, Current Contents $\AA /$ Clinical Medicine,
Dovepress

Journal Citation Reports/Science Edition, EMBase, Scopus and the Elsevier Bibliographic databases. The manuscript management system is completely online and includes a very quick and fair peer-review system, which is all easy to use. Visit http://www.dovepress.com/ testimonials.php to read real quotes from published authors. 